\title{
SPECIAL ISSUE EDITORIAL
}

\section{Wing-On LEE, Chenri HUI, LOW Ee Ling}

\section{Equity, Resilience, and Achievements in High Performing Asian Education Systems}

In the latest 2012 PISA results, the top performers were all Asian countries and regions. Common among these high performing education systems is the emergence of quality improvement in education as a means of achieving equity. This replaces the conventional focus on system inputs in education mainly influenced by the economic and sociological beliefs of the time, based on the human capital theory and the compensatory theory for the disadvantaged as a means of rectifying inequities. Improvement in education has resulted in more complicated scenarios that can potentially improve quality, e.g., closing the achievement gap by improving overall performance, and creating opportunities for low achievers to aspire to higher achievement. The PISA results also provide more information about the intrinsic reasons behind high achievement. For example, the measurement of resilience shows that low achievers are fighting to improve, despite disadvantaged backgrounds and situations, e.g., socioeconomic status, parents' education background, and residential status. In addition, intrinsic interest and a strong belief in learning effort are also proved to be significant factors in high achievement that may overcome disadvantaged learning environments for individual students. Further, recent developments in student-centered participative pedagogies, such as peer tutoring, collaborative learning, and knowledge building, have turned students into active learning agents. They are no longer passive classroom recipients of learning, but rather are active learners in seamless learning scenarios that are helping high performing education systems to enhance learning outcomes.

The papers in this special issue of Frontiers of Education in China address a

\section{Wing-On LEE ( $\square$ )}

Open University of Hong Kong, Hong Kong, China

E-mail: wolee@ouhk.edu.hk

\section{Chenri HUI, LOW Ee Ling}

Strategic Planning and Academic Quality, National Institute of Education, Nanyang Technological University, 637616 Singapore, Singapore 
number of topics relevant to educational equity and quality in general. They focus on different education contexts, including Shanghai, Hong Kong, Taiwan, South Korea, and Japan, covering equity and quality issues from the elementary school level up to university level. Together, the papers provide a picture of the equity issues which face the education sector as a whole.

In the first paper, "Achieving equity and quality in Japanese elementary schools: Balancing the roles of state, teachers, and students," Parmenter seeks to explore the perspectives of elementary school educators on the roles of the state, schools, teachers, and students themselves in relation to the task of achieving and maintaining equity and quality in the Japanese education system. The author purposefully chose a semi-rural Japanese elementary school as the research site, as most elementary schools are outside the major urban areas. As the author points out, Japan is not only one of the high performing education systems according to PISA rankings, but also noted for the equity in performance and student resilience. Qualitative research, such as this paper, is judged by the author to be of particular importance to complement and understand the findings of large scale assessments such as PISA. Indeed, the author presents powerful analysis that shows factors that contribute to: (1) education equity and quality in Japanese elementary schools; and (2) student motivation and resilience. Analysis reveals various factors at the level of the state, schools, teachers, parents, and students themselves. Among all the factors, it appeared that teachers play a key mediating role in equity and quality. They also play a key role in motivating students and fostering resilience among them. Of particular note is that to teachers in the school studied, education quality is measured by the development of the hearts and minds of each student, rather than primarily by test scores. This is a significant reminder, as over-emphasis on outcome assessment may dehumanize and depersonalize education, and it is when students find intrinsic value in themselves that they will develop the intrinsic motivation to learn to achieve or overcome all the constraints surrounding them.

The paper written by Kennedy and Li explores the factors accounting for Hong Kong students' achievements in civic learning. Given its importance in developing young people to be future citizens, the authors strongly argue for more research attention on civic learning. They note that much of the debate on Asian students' achievement in international assessments has been on subjects such as mathematics, science, and reading. Little is known about the reasons for 
Asian students' success in civic learning. Results from multi-level quantitative analysis of this paper reveal two sets of predictors that could have the potential to influence students' achievement in civic learning. They are: (1) individual student dispositions and responses to classroom influences; and (2) school level influences that characterize the environment of the school. It appears that school factors such as classroom climate and principal's perceptions of students' sense of belonging make a considerable difference to Hong Kong students' level of civic learning. Based on this result, the authors highlight the responsibility that teachers and schools have in preparing Hong Kong's future citizens. In addition, the authors find that family background measured by factors such as socioeconomic status and immigrant background have relatively little effect on Hong Kong students' civic learning. The authors claim that this result confirms the findings from PISA 2012 that Hong Kong had above average performance on equity in education. The authors also suggest that the lack of effect of background variables might reveal a relatively high level of student resilience. However, the authors strongly recommend to do further research on student resilience to provide stronger empirical evidence.

The paper by Zhao, Zhu, and Ruan entitled, "Configuration of the teacher-state relationship: The Shanghai experience," explores how Shanghai configures the teacher-state relationship and builds a teaching force against the background of China's centralized education. This study is unique in that it goes beyond teachers' instructional activities and explores how the teaching profession is influenced by teachers' interactions with social actors in political, social, and economic areas. Data for this research includes major educational policies from China's central government and the Shanghai municipal government as well as empirical studies from Shanghai. The authors adopted a three-dimensional framework to analyze the dynamic relationship between teachers and the State, specifically: (1) teacher-profession-state; (2) teacher-school-state; and (3) teacher-market-state. It appeared that Shanghai seems to make more effort to decentralize its education system to pursue quality and efficiency. The authors report that although the state has changed the means of controlling teachers, there appears to be a lack of teacher empowerment in the reform process and a lack of professional satisfaction. The findings show that schools now have become powerful actors between teachers and the state in terms of hiring and managing teachers. In addition, as teachers have shifted from being government officials to 
being school employees, the labor market has become an influential factor on teachers' lives. Unsurprisingly, teachers' incomes in Shanghai are relatively higher than in many other places in the Chinese Mainland due to its higher level of economic development. Although great achievements have been made in enhancing the teaching profession, Shanghai still faces challenges in overall professionalization.

The paper by Kim explores issues of equity and quality of teaching and learning for international students in South Korean higher education institutions. It focuses on the views of international students in South Korean universities on whether they have received education provisions that are inclusive, equitable, and anti-discriminatory. It also explores the challenges they face in their campus life and the issue of hidden racism in South Korean universities. Data for this research consists of qualitative interviews with six international students from different backgrounds and studying in four different universities in South Korea. The author identified three issues that affect equity and quality of education for international students: (1) the lack of an inclusive policy for international students; (2) racism embedded in routine practice and culture across the campus; and (3) alienation in teaching and learning activities. The author constructs a strong case that it is time for South Korean universities to reform their social, cultural, and institutional systems to embrace diversity. It is suggested that South Korean universities implement multicultural education at the university level and prepare reflective educators who embrace diversity in the campus.

The paper by Lin is entitled "Reigniting the passion for learning: A systematic attempt in Taipei." It investigates Taipei's responses to the M-shape phenomenon, the gap between higher and lower achievers in senior high schools. PISA 2012 results indicate that the M-shape distribution of Taiwanese students is top of the 65 countries and regions participating in the study. The author argues that "the systematic attempt of Taipei to improve teaching and learning and consequently to reignite teachers' and students' passion for learning is a good way to offer an educational environment with better equity." (p. 361) This paper reports three key initiatives introduced in Taipei: (1) the "curriculum development circle" to increase inter-school collaboration; (2) the Leading Programme of Curriculum and Instruction for Senior High and Vocational School; and (3) the promotion of student-centered teaching. As the author notes, all the initiatives indicate a focus on the basics of teaching and learning. The author points out that an 
improvement in overall teaching practices and school culture will eventually improve equity in school education.

Through these papers, this special issue hopes to advance our understanding of the various dimensions of student learning in Asia's high performing education systems. Each paper sheds nuanced light on equity and quality issues in education. We hope this special issue will catalyze more research into this area and trust that with soundly researched evidence we will have a better chance of achieving, maintaining, and improving education equity and quality, as well as fostering stronger resilience among students. 